\title{
The effects of short-term resistance program on vertical jump ability in elite male volleyball players during the competition season Efectos de un entrenamiento de fuerza de corta duración sobre la capacidad de salto vertical en
jugadores de voleibol de elite durante la temporada
}

\author{
Miguel Sánchez Moreno, Carlos GarcíaAsencio, Juan José González Badillo \\ Pablo de Olavide University
}

\begin{abstract}
The aim of this study was to describe the effects of 6 weeks of combined strength and jump training which incorporated moderate loads and high intensity contractions on the vertical jump ability (VJ), loaded jumps and velocity of execution in full squat in a group of professional male volleyball players during the competition season. It was hypothesized that the VJ improved by cross combined strength and jump training both characterized by high velocity of execution $(>1 \mathrm{~m} / \mathrm{s})$. The participants in this study were twelve players who competed in the first national division of the Spanish National League during the 2011-2012 season. The neuromuscular performance was estimated by unloaded (CMJ) and loaded countermovement jumps $\left(\mathrm{CMJ}_{\text {loaded }}\right)$ height $(\mathrm{cm})$; and by velocity of displacement in the concentric phase of full squat $(\mathrm{FS})(\mathrm{m} / \mathrm{s})$. There was a significant increase in $\mathrm{CMJ}$ and $\mathrm{CMJ}_{\text {laaded }}$ after 6-week of training ( $5 \%, \mathrm{p}<0.01$; and $5.7 \%, \mathrm{p}<0.05$; respectively). These changes were accompanied by a small and moderate value of Effect Size (0.47, and 0.67; respectively). No significant differences were observed for velocity of displacement in FS. The linear correlation analysis showed a single moderate correlation statistically significant between the changes in CMJ-CMJ ${ }_{\text {laaded }}$ and CMJ-FS ( $\mathrm{r}=0.62$ and $r=0.59, \mathrm{p}<0.05$; respectively). Albeit speculative, our results suggest that the use of moderate loads could be enough to improve the vertical jump performance, since in our study a load equivalent to 60\% 1RM in the FS was not exceeded and jumping exercises were performed with light loads. Keywords: Resistance training; Plyometric exercise; Vertical jump; Lower Extremity, Velocity, Strength.
\end{abstract}

Resumen: El objetivo de este estudio fue describir los efectos de 6 semanas de entrenamiento combinado de fuerza y salto, el cual incorpora cargas moderadas e intensidades de contracción altas, sobre la capacidad de salto vertical, saltos con cargas y la velocidad de ejecución en el ejercicio de sentadilla en un grupo de jugadores profesionales de voleibol durante la temporada de competición. Se estableció la hipótesis de que el salto vertical mejoro por el uso combinado de entrenamiento de fuerza y salto, ambos caracterizados por una alta velocidad de ejecución $(>1 \mathrm{~m} / \mathrm{s})$. El rendimiento neuromuscular fue estimado por la altura $(\mathrm{cm})$ del salto sin cargas (CMJ), salto con cargas $\left(\mathrm{CMJ}_{\text {loaded }}\right)$, y por la velocidad $(\mathrm{m} / \mathrm{s})$ de desplazamiento en la fase concéntrica en la sentadilla completa (FS). Tuvo lugar un incremento significativo en $\mathrm{CMJ}_{\text {y }} \mathrm{CMJ}_{\text {loaded }}$ después de 6 semanas de entrenamientos ( $5 \%$, p $<0.01 ; \mathrm{y} 5.7 \%$, $\mathrm{p}<0.05$; respectivamente). Estos cambios fueron acompañados por un valor de Tamaño del Efecto pequeño y moderado (0.47, and 0.67; respectivamente). No se observaron diferencias significativas en la velocidad de desplazamiento en FS. El análisis de correlación lineal mostró una correlación moderada estadísticamente significativa entre los cambios en $\mathrm{CMJ}_{-} \mathrm{CMJ}_{\text {loaded }}$ y CMJ-FS ( $\mathrm{r}=0.62$; y r=0.59, $\mathrm{p}<0.05$; respectivamente). Aunque algo especulativo, nuestros resultados sugieren que el uso de cargas moderadas podría ser suficiente para mejorar el rendimiento del salto vertical, ya que en nuestro estudio no se excedió una carga equivalente al 60\% de 1RM en FS y los ejercicios de saltos también fueron realizados con cargas ligeras. Palabras claves: Entrenamiento con resistencias, ejercicios pliométricos, salto vertical, extremidad inferior, velocidad, fuerza.

\section{Introduction}

Volleyball is a sport characterized by the requirement to perform movements commonly considered as explosives, such as jumps, arm hitting and short displacements. The attack and blocking are crucial game actions for attaining victory in top-level competition (RodríguezRuiz, Quiroga, Miralles, Sarmiento, De Saá \& García-Manso, 2011). Part of the success of these actions is determined by the height at which they are performed (Voigt \& Vetter, 2003), which are influenced by the vertical jump ability of the players.

Some authors suggest that only skill-based conditioning program could not be enough for the improvement of vertical jump performance in volleyball players and, the combination of it with strength training could be a better stimulus for specific volleyball conditioning (Trajkovic, Milanovic, Sporis, Milic \& Stankovic, 2012). The way to improve vertical jump in physically active athletes is a topic that has been studied many times. It has been observed improvement in vertical jump from training approaches that included (a) heavy-resistance-training program using the squat exercise (Adams, O'Shea, O'Shea \& Climstein, 1992; Newton, Rogers, Volek, Häkkinen \& Kraemer, 2006; Sáez-Sáez De Villarreal, Izquierdo \& González-Badillo, 2011) (relative intensity $>70 \%$ of 1 repetition maximum [1RM]); (b) power-training program using exercises such as loaded squat jump (Newton, Rogers,

Fecha recepción: 11-05-14- Fecha envío revisores: 12-05-14- Fecha de aceptación: 03-06-14 Miguel Sánchez Moreno

C/Rafael Alberti, no $14 / 4^{\circ} \mathrm{B}$

41008, Sevilla.

msanmor@hotmail.com
Volek, Häkkinen \& Kraemer, 2006; Sáez-Sáez De Villarreal, Izquierdo \& González-Badillo, 2011) (with the load that produced maximal mechanical power (MP) or loads close to this, 70 to $90 \% \mathrm{MP}$ ), or Olympic movements (Arabatzi, Kellis \& Sáez-Sáez De Villarreal, 2010; Channel \& Barfield, 2008; Tricoli, Lamas, Carnevale \& Ugrinowitsch, 2005) (high relative loads, $>75 \%$ of $1 \mathrm{RM}$ ); (c) plyometric training program with no added external resistance to the body weight (Adams, O’Shea, O’Shea \& Climstein, 1992; Sáez-Sáez De Villarreal, Izquierdo \& González-Badillo, 2011; Sáez-Sáez De Villarreal, González-Badillo \& Izquierdo, 2008; Sáez-Sáez De Villarreal, Requena, Arampatzi \& Salonikidis, 2010), and (d) by combining some of them (Adams, O'Shea, O’Shea \& Climstein, 1992; Sáez-Sáez De Villarreal, Izquierdo \& González-Badillo, 2011; Wilson, Newton, Murphy \& Humphries, 1993). Same authors suggest that the best way to improve vertical jump is through the combination of plyometric training with resistance training (Perez-Gomez \& Calbet, 2013). This improvement in the vertical jump despite the different strength training methods used might be attributed to the fact that the athletes in those studies were not highly trained. Some authors have shown that athletes with low level of strength exhibit significant improvement in vertical jump, regardless the training stimulus (Adams, O’Shea, O’Shea \& Climstein, 1992; Sáez-Sáez De Villarreal, González-Badillo \& Izquierdo, 2008), while previously strength-trained athletes may exhibit limited improvements in vertical jump (Häkkinen, Komi \& Alén, 1985).

McLellan (2011) reported that the maximal unloaded vertical jump is primarily determined by Peak Rate of Force Development (PRFD), suggesting that training methods in order to improve PRFD can lead to improved unloaded vertical jump. Häkkinen et al. (1985) found that high velocity training with light-load movements appears to be an 
important aspect to consider for improving RFD in isometric actions. Other authors (Sáez-Sáez De Villarreal, Izquierdo \& González-Badillo, 2011) suggest that training conducted at low and high velocity had the same effect on vertical jump, while Behm and Sale (1993) argued that it was the intention to move the load as quickly as possible which resulted in a fast velocity-specific training effect.

There are not many studies which have carried out a detailed analysis of the strength training program used in professional volleyball players during the competition season. We only found two studies accomplished with male volleyball players (Marqués, González-Badillo \& Kluka, 2006; Stanganelli, Dourado, Oncken, Mançan \& da Costa, 2008) and three studies with women (Newton, Rogers, Volek, Häkkinen \& Kraemer, 2006; Häkkinen, 1993; Marqués, Van Den Tillaar, Vescovi \& GonzálezBadillo, 2008). But these studies do not analyze the effect of the application of moderate loads in both full squat and loaded jumps on improving jumping ability in these athletes. Thus, the purpose of this study was to examine the effect of 6 weeks of combined strength and jump training, both characterized by the use of moderate loads, on the unloaded vertical jump height, loaded vertical jump height and velocity of execution in full squat in a group of professional male volleyball players during the competition season. It was hypothesized that the vertical jumping ability improved by cross combined strength and jump training during the competitive season in professional male volleyball players highly trained in the jumping exercise.

\section{Material and Methods}

Twelve professional volleyball players (age [mean \pm SD] $=23.1 \pm 3.4$ years, height $=191.25 \pm 0.06 \mathrm{~cm}$, body mass $=83.3 \pm 9.1 \mathrm{~kg}$ ) playing in the first national division of the Spanish National League during the 2011-2012 season participated in this study. All participants were informed about the experimental procedures and possible risks and benefits associated with the study. Because the ethical considerations discussed by Kraemer (2005) and the difficulties expressed by Marques et al. (2008), it was not possible to include a control group which avoids training. The study was conducted in accordance with the Declaration of Helsinki II and approved by the Ethics Committee of Pablo de Olavide University, Seville, Spain.

\section{Training protocols}

Training took place 2-3 d•wk ${ }^{-1}$ during 6 weeks ( 14 sessions), with each season lasting approximately 50 minutes and consisting of the following components: 10 minutes of standard warm-up (7 minutes submaximal running, stretching exercises for 3 minutes), 35 minutes of specific strength training; and 5 minutes of cool down including stretching exercises. All training sessions were supervised. Before the initiation of the training periods, the athletes were instructed as to the proper execution of all the exercises to be done during the training period. The resistance exercises were full squat, half squat, loaded jump and hang power clean, executed in the same order as shown. Table 1 provides a detailed description of the training routine. Three-minute rest intervals were permitted between all sets and exercises. All resistance training was completed in the morning and was supervised for one of the investigators.

\section{Testing Procedures}

All athletes were evaluated on two occasions: September (test 1: first week) and October (test 2: eighth week), during the first six weeks of competition. All tests were performed after a 48-hour period of complete rest after the last competition, at the same time of day, in the same order and by the same researchers. The participants were carefully familiarized with the equipment and the test protocols using 2-3 submaximal attempts. We performed a general warm-up consisting of 5 minutes of continuous run followed by 5 sets of 30 meters running at progressive velocity.

Unloaded Countermovement Jump (CMJ). The CMJ test was performed using an Optojump photocell system (Microgate, Bolzano, Italy) to measure flight time. Jump height was determined using stan- dard flight-time calculation. Three trials were completed with 2 minutes of rest between trials. The average of the three values was used for the subsequent statistical analysis. The intraclass correlation coefficient (ICC) and coefficient of variation (CV) were calculated for CMJ height obtaining ICC values of 0.99 (0.98-0.99) and a CV of $1.84 \%$.

Loaded Countermovement Jump ( $\left.\mathrm{CMJ}_{\text {loaded }}\right)$. The test consists of performing a vertical jump with the barbell behind the head on the top of the back. The bar weight of the machine type Smith machine $(17 \mathrm{~kg})$ was then progressively increased in 20, 10 and $5 \mathrm{~kg}$ increments for each repetition, until the athletes reached a height of about $20 \mathrm{~cm}$. We performed a 3 minute rest between each repetition. It was strictly controlled that the bar did not separate from neck at end of the concentric phase, this could provide measurement errors. The height of jump was determined in the same manner as the test CMJ.

Full squat(FS). FS test was performed on the same machine as the $\mathrm{CMJ}_{\text {loaded }}$, placing the barbell behind the head on the top of the back. From this position, there was a deep flexion of the legs to exceed the horizontal, and then there was an immediate extension of the legs to the fullest extent. Subjects were instructed to perform a controlled eccentric phase and a concentric phase at the highest possible velocity. After warm-up, the bar was increased in 20 or $10 \mathrm{~kg}$ increments for each set, from an average velocity in the propulsive phase of movement (MedinaSánchez, Pérez \& González-Badillo, 2010) approximately of $1.4 \mathrm{~m} / \mathrm{s}$ until the average velocity about $1 \mathrm{~m} / \mathrm{s}$. The subjects performed between 1 and 4 attempts with each load. The best result accompanied by a correct execution was used for the subsequent statistical analysis. We performed a 3 minute rest among each load.A dynamometer isoinercial T-Force (T-Force System, Ergotech, Murcia, Spain) was used for measuring the velocity of displacement $(1.000 \mathrm{~Hz})$.

\section{Statistical analysis}

Differences in vertical jump height and velocity of execution in full were compared using paired t-test. Because of the small sample size, effect size(ESs) was calculated according to Hedges and Olkin's (1985). The scale used for the interpretation was the one proposed by Rhea (2004) for highly trained athletes. Pearson correlation coefficients (r) were used to study the relationship between changes in the different exercises. Statistical difference was accepted at alpha level of $p d<0.05$.

\begin{tabular}{|c|c|c|c|c|c|}
\hline \multirow[b]{2}{*}{ Weeks } & \multicolumn{5}{|c|}{ Exercises } \\
\hline & $\mathrm{s} / \mathrm{w}$ & FS & HS & $\mathrm{CMJ}_{\text {loaded }}$ & Power clean \\
\hline 1 & 2 & $3 \times 6(1 \mathrm{~m} / \mathrm{s}-15 \%)$ & $3 \times 6100 \%$ & $3 \times 540 \%$ & $3 \times 6$ \\
\hline 2 & 2 & $3 \times 8(1 \mathrm{~m} / \mathrm{s}-15 \%)$ & $3 \times 6100 \%$ & $3 \times 540 \%$ & $3 \times 6$ \\
\hline 3 & 3 & $3 \times 8 \begin{array}{c}(1 \mathrm{~m} / \mathrm{s}-15 \%) 3 \times 6 \\
(1 \mathrm{~m} / \mathrm{s}-7 \%)\end{array}$ & $\begin{array}{c}3 \times 6 \text { 100\% 3x6 } \\
105 \%\end{array}$ & $3 \times 550 \%$ & $3 \times 6$ \\
\hline 4 & 3 & $3 \times 6(1 \mathrm{~m} / \mathrm{s}-7 \%)$ & $3 \times 6105 \%$ & $3 \times 550 \%$ & $3 \times 5$ \\
\hline 5 & 2 & $3 \times 4(1 \mathrm{~m} / \mathrm{s})$ & $3 \times 5110 \%$ & $3 \times 460 \%$ & $3 \times 5$ \\
\hline 6 & 2 & $3 \times 4(1 \mathrm{~m} / \mathrm{s})$ & $3 \times 5110 \%$ & $3 \times 460 \%$ & $3 \times 5$ \\
\hline \multicolumn{6}{|c|}{ Training summary } \\
\hline Exercises & & Intensities & Sets $x$ reps $\S$ & $\%$ total rep $\dagger$ & \\
\hline \multirow[t]{3}{*}{ FS } & & $1 \mathrm{~m} / \mathrm{s}-15 \%$ & 108 & 47 & \\
\hline & & $1 \mathrm{~m} / \mathrm{s}-7 \%$ & 72 & 32 & \\
\hline & & $1 \mathrm{~m} / \mathrm{s}$ & 48 & 21 & \\
\hline \multirow[t]{3}{*}{ HS } & & $100 \% \mathrm{H} 20$ & 54 & 39 & \\
\hline & & $105 \% \mathrm{H} 20$ & 54 & 39 & \\
\hline & & $110 \% \mathrm{H} 20$ & 30 & 22 & \\
\hline \multirow{3}{*}{$\mathrm{CMJ}_{\text {laded }}$} & & $40 \% \mathrm{H} 20$ & 30 & 26 & \\
\hline & & $50 \% \mathrm{H} 20$ & 60 & 53 & \\
\hline & & $60 \% \mathrm{H} 20$ & 24 & 21 & \\
\hline Power clean & & -- & 198 & -- & \\
\hline
\end{tabular}

$\mathrm{m} / \mathrm{s}=$ velocity of displacement of the bar during the propulsive concentric phase of the full squat $\left(1 \mathrm{~m} / \mathrm{s}^{\sim}\right.$ $60 \% 1 \mathrm{RM}$ ); $\mathrm{H} 20$ = weight which athletes reached a height of about $20 \mathrm{~cm}$ in $\mathrm{CMJ}_{\text {loaded }}$ Hang power dean; $3 \times 6=3$ series $x 6$ repetitions with the maximum load that allows a correct technical execution. $\S$ The total number of repet itions lifted duing the training cycle with each intensity. †Percent age of total repetitions perfomed with each intensity.

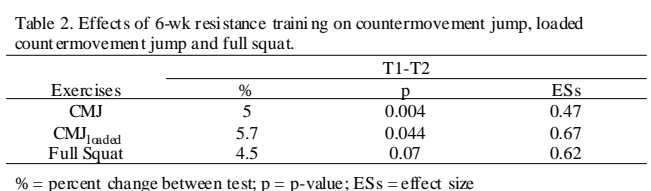

$\%=$ percent change between test; $\mathrm{p}=\mathrm{p}$-value; ESs $=$ effect size

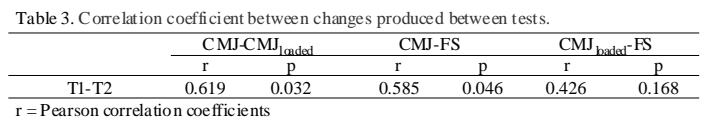




\section{Results}

There was a significant increase in $\mathrm{CMJ}$ and $\mathrm{CMJ}_{\text {loaded }}$ after 6week of training ( $5 \%, \mathrm{p}<0.01$; and $5.7 \%, \mathrm{p}<0.05$; respectively). These changes were accompanied by a small and moderate value of Effect Size ( 0.47 and 0.67 ; respectively). No significant differences were observed for velocity of displacement in FS (table 2). The linear correlation analysis showed a single moderate correlation statistically significant between the changes in CMJ-CMJ ${ }_{\text {loaded }}$ and CMJ-FS ( $\mathrm{r}=0.62$ and $\mathrm{r}=0.59$, $\mathrm{p}<0.05$; respectively) (table 3 ).

\section{Discussion}

The main aim of our study was to evaluate the effect of strength training on jumping ability during the competition phase in professional male volleyball players. The results of our study showed a significant improvement after 6-wk training period in $\mathrm{CMJ}$ and $\mathrm{CM}_{\text {Jloadec }}$

We have not found similar studies performed with elite senior male volleyball players, but we found a study carried out with women volleyball players (Newton, Rogers, Volek, Häkkinen \& Kraemer, 2006). During the first 7-wk of this study lower limb with «heavy loads» were trained, but unfortunately it is not indicated in the article what the real value of these «heavy loads» or «traditional resistance training» is. In addition, during the 4 remaining weeks they were trained with a «ballistic training», which should be interpreted as a weight training less than in the first 7-wk done at high velocity and with loads close to that at which maximum power is reached. After the 7-wk training period vertical jump performance decreased significantly, and improved in the last 4 wk significantly with respect to test 2 but not with respect to the initial test. These authors suggested that the decrease in the first 7-wk is related to a depressed of the neuromuscular system due to the combination of training, game play and skills practice precluding adequate recovery. By contrast, in our study the improvements were statistically significant after 6-wk and the training were also performed together with specific training and competitions. Results similar to ours were observed by Marques et al. (2008)after 12-wk resistance training with training loads ranging from 50 to $75 \%$ of 1RM, and by Häkkinen (1993) after 10-wk training period (loads $>75 \% 1 \mathrm{RM}$ ), in competitive phase, but with an improvements of 3.8\% and $4.5 \%$, respectively, compared with $5 \%$ in our case. Other authors (Voelzke, Stutzig, Thorhauer \& Granacher, 2012) observed no changes in CMJ after 5-wk resistance training (loads of 85\% 1RM) in eight professional male volleyball players in preseason. The comparison of the results of these studies suggests that high loads do not produce better results on vertical jump performance, since in our study a load equivalent to $60 \%$ of the $1 \mathrm{RM}$ in the FS was not exceeded, and jumping exercises were performed with light loads, so the velocity of execution in both exercises was high. The superiority of the effect of the $\mathrm{CMJ}_{\text {loaded }}$ with light loads (30\% 1RM) against heavy loads (80\% 1RM) has also been observed in other studies such as that conducted by McBride et al. (2002). These results suggest that the specificity of training, which in this case is expressed by the proximity of the velocities of execution of the training exercises to the velocity of execution of the vertical jump, seems to be determinant for the performance.

In addition to CMJ exercise, our study also measured the effect of training on $\mathrm{CMJ}_{\text {loaded }}$ and FS. After the training period there were significant improvements in $\mathrm{CMJ}_{\text {loaded }}(5.7 \%, \mathrm{p}=0.04)$ and no-significant improvements in FS (4.5\%, p=0.07) both with a moderate ESs ( 0.67 and 0.62 , respectively). The improvements in both exercises can be considerate important, although, due to the small number of athletes, FS exercise did not reach statistical significance. This apparent lack of improvement is offset by the moderate ESs that FS has submitted. It is notable that FS exercise improved less than the $\mathrm{CMJ}$ and $\mathrm{CMJ}_{\text {loaded }}$ Typically, the improvement in strength with high loads is bigger than with light loads, because the maximum strength, manifested with high loads, has a wider room for improvement than the absolute velocity of muscle shortening (velocity without loads). However, in our case the trend was the opposite. It is likely that the specificity of training had more influence on the effects (vertical jump ability) than improving maximum strength at high loads. Therefore, considering that the priority aim of the study was to improve the jump without loads, because this is the specific performance, the training loads applied in the present study seem to be suitable for the purpose it was intended.

However, improvements in strength and jump do not appear to have been independent, instead according to the degree of correlation found among changes in the variables of $\mathrm{CMJ}, \mathrm{CMJ}_{\text {loaded }}$ and FS (table 3 ), it can be suggested that the improvement in the strength has also played an important role in the results of CMJ. The value of correlations between changes in CMJ-CMJ ${ }_{\text {loaded }}$ and CMJ-FS are considerable, and we understand that the value of these correlations is a surprising finding of our study, since a correlations value of 0.62 and 0.59 , respectively, between changes in two variables suggests the existence of a common element causing both variables change. If the relationship is direct, as in this case, these results suggest that to improve the CMJ it is also necessary to improve leg strength, when measured through a FS. Or other words, the improvement in the FS explain approximately 34\% $\left(0.59^{2} \times 100\right)$ of the improvement in the CMJ.

Greater improvement in $\mathrm{CMJ}_{\text {loaded }}$ has been observed in the study of Marques et al. (2008) which can be explained by the higher maximum intensity used in squat, approximately $75 \%$ of $1 \mathrm{RM}$, which led to an improvement of the strength in squat (13\%), and by the intensity used in $\mathrm{CMJ}_{\text {loded }}$ close to $100 \%$ of the load at which the maximum power was reached, resulting in an improvement in this test between 9 and $12 \%$. A greater improvement at low velocity, typical of a squat with high loads, may further explain the velocity changes with medium loads $\left(\mathrm{CMJ}_{\text {loaded }}\right)$, since when greater load is moved, greater variance of the velocity is explained by maximum strength (Verkhoshansky, 1986). However, these higher loads had less effect on the CMJ (3.9\%) than in our study (5\%), suggesting that a greater load does not necessarily produce better results on high-velocity action. In addition, the relationship between the changes in CMJ and FS was of 0.24 , while ours study was 0.59 . These results highlight the need to find the right balance between strength and velocity and its relation to the specific velocity of the exercise in which we want to improve.

\section{Conclusions}

Albeit speculative, our results suggest that the use of moderate loads could be enough to improve the vertical jump performance, since in our study a load equivalent to $60 \% 1 \mathrm{RM}$ in the FS was not exceeded and jumping exercises were performed with moderate loads. These results suggest that the specificity of training, which in this case is expressed by the proximity of the velocities of execution of the training exercises to the velocity of execution of the vertical jump, seems to be determinant for the performance. The improvement in leg strength when it is measured through the FS explains about $34 \%$ of the improvement in the vertical jump when both exercises are trained with light load. The results of our study allow us to consider that it is not necessary to apply a heavy loads phase or «traditional strength training» before a light loads phase or «ballistic training», as it has been proposed traditionally, in the case of highly trained athletes. Further studies are required to determine the appropriate combination of loads and time training to allow further improvement and to sustain these improvements throughout the competitive phase.

\section{Acknowledgments}

The authors would like to thank Sport training laboratory, Faculty of Sport Science, Pablo de Olavide University and volleyball team, CajaSol-Juvasa Esquimo, for their collaboration in the development of this work. No sources of funding were used to assist in the preparation of this work. The authors have no conflicts of interest that are directly relevant to the content of this work. 


\section{References}

Adams, K., O’Shea, J. P., O’Shea, K. L., \& Climstein, M. (1992). The effect of six weeks of squat, plyometric and squat-plyometric training on power production. The Journal of Applied Sport Science Research, 6, 36-41.

Arabatzi, F., Kellis, E., \& Sáez-Sáez De Villarreal, E. (2010). Vertical Jump Biomechanics after Plyometric, Weight Lifting, and Combined (Weight Lifting + Plyometric) Training. Journal of Strength and Conditioning Research, 24, 2440-2448.

Behm, D. G., \& Sale, D. G. (1993). Velocity specificity of resistance training. Sports Medicine, 15, 374-378.

Channel, BT., \& Barfield, J. P. (2008). Effect of olympic and traditional resistance training on vertical jump improvement in high school boys. Journal of Strength and Conditioning Research, 22, 15221527.

Häkkinen, K. (1993). Changes in physical fitness profile in female volleyball players during the competitive season. The Journal of sports medicine and physical fitness, 33, 223-232.

Häkkinen, K., Komi, P. V., \& Alén, M. (1985). Effect of explosive type strength training on isometric force- and relaxation-time, electromyographic and muscle fiber characteristics of leg extensor muscles. Acta Physiological Scandinavica, 125, 587-600.

Hedges, L. V., \& Olkin, I. (1985). Statistical Methods for Meta-Analysis, New York: Academic Press.

Kraemer, W. J.(2005). The body of knowledge: use and professionalism. Strength \& Conditioning Journal, 27, 33-35.

Marqués, M. C., González-Badillo, J. J., \& Kluka, D. (2006). Inseason strength training male professional volleyball athletes. Strength \& Conditioning Journal, 28, 6-12.

Marqués, M. C., Van Den Tillaar, R., Vescovi, J. D., \& GonzálezBadillo, J. J.(2008). Changes in strength and power performance in elite senior female professional volleyball players during the inseason: a case study. Journal of Strength and Conditioning Research, 22, 1147-1155

McBride, J. M., Triplett-McBride, T., Davie, A., \& Newton, R. U. (2002). The effect of heavy- vs. light-load jump squats on the development of strength, power, and speed. Journal of Strength and Conditioning Research, 16, 75-82.

McLellan, C. P., Lovell, D. I., \& Gass, G. C. (2011). The role of rate of force development on vertical jump performance. Journal of Strength and Conditioning Research, 25, 379-385.

Medina-Sánchez, L., Pérez, C., \& González-Badillo, J. J. (2010) Importance of the propulsive phase in strength assessment. International Journal of Sports Medicine, 31, 123-129.

Newton, R. U., Rogers, R.A., Volek, J. S., Häkkinen, K., \& Kraemer, W. J. (2006). Four weeks of optimal load ballistic resistance training at the end of season attenuates declining jump performance of women volleyball players. Journal of Strength and Conditioning Research, 20, 955-961.
Perez-Gomez, J., \& Calbet, J.A. L. (2013). Training methods to improve vertical jump performance. The Journal of sports medicine and physical fitness, 53, 339-357.

Rhea, M. R. (2004). Determining the magnitude of treatment effects in strength training research through the use of the effect size. Journal of Strength and Conditioning Research, 18, 918-920.

Rodríguez-Ruiz, D., Quiroga, M. E., Miralles, J. A., Sarmiento, S., De Saá, Y., \& García-Manso, J. M. (2011). Study of the technical and tactical variables determining set win or loss in top-level European men's volleyball. Journal of Quantitative Analysis in Sports, 7, 113.

Sáez-Sáez De Villarreal, E., González-Badillo, J. J., \& Izquierdo, M. (2008). Low and moderate plyometric training frequency produces greater jumping and sprinting gains compared with high frequency. Journal of Strength and Conditioning Research, 22, 715-725.

Sáez-Sáez De Villarreal, E., Izquierdo, M., \& González-Badillo, J. J. (2011). Enhancing jump performance after combined vs. maximal power, heavy-resistance, and plyometric training alone. Journal of Strength and Conditioning Research, 25, 3274-3281.

Sáez-Sáez De Villarreal, E., Requena, B., Arampatzi, F., \& Salonikidis K. (2010). Effect of plyometric training on chair-rise, jumping and sprinting performance in three age groups of women. The Journal of sports medicine and physical fitness, 50, 166-173.

Stanganelli, L., Dourado, A. C., Oncken, P., Mançan, S., \& da Costa, S. C. (2008). Adaptations on jump capacity in brazilian volleyball players prior to the under-19 world championship. Journal of Strength and Conditioning Research, 22, 741-749.

Trajkovic, N., Milanovic, Z., Sporis, G., Milic, V., \& Stankovic, R. (2012). The effects of 6 weeks of preseason skill-based conditioning on physical performance in male volleyball players. Journal of Strength and Conditioning Research, 26, 1475-1480.

Tricoli, V., Lamas, L., Carnevale, R., \& Ugrinowitsch, C. (2005). Shortterm effects on lower-body functional power development: weightlifting vs. vertical jump training programs. Journal of Strength and Conditioning Research, 19, 433-437.

Verkhoshansky, Y.(1986). Fundamentals of special strength training in sport, Livonia: Michigan Sportivny Press.

Voelzke, M., Stutzig, N., Thorhauer, H. A., \& Granacher, U. (2012). Promoting lower strength in elite volleyball players: Effects of two combined training methods. Journal of Science and Medicine in Sport, 15, 457-462.

Voigt, H., \& Vetter, K. (2003). The value of strength-diagnostic for the structure of jump training in volleyball. European Journal of Sport Science, 3, 1-10.

Wilson, G. J., Newton, R. U., Murphy, A. J., \& Humphries, B. J. (1993). The optimal training load for the development of dynamic athletic performance. Medicine \& Science in Sports \& exercise, 25, 1279-1286.

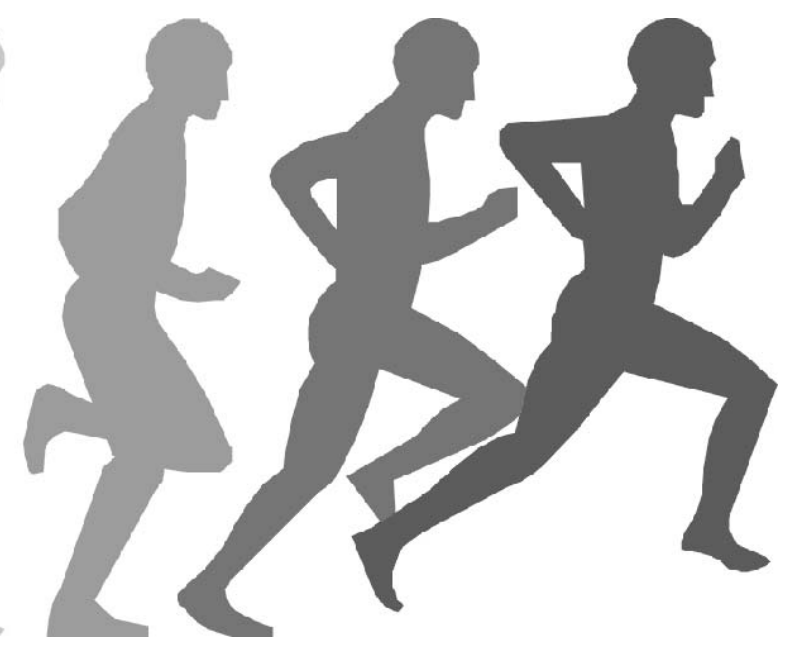

